\title{
Leaching of Metal Ions from Blast Furnace Slag by Using Aqua Regia for $\mathrm{CO}_{2}$ Mineralization
}

\author{
Jun-Hwan Bang, Seung-Woo Lee, Chiwan Jeon, Sangwon Park, Kyungsun Song, Whan Joo Jo and \\ Soochun Chae*
}

$\mathrm{CO}_{2}$ Sequestration Department, Korea Institute of Geoscience and Mineral Resources (KIGAM),

124 Gwahang-no, Yuseong-gu, Daejeon 34132, Korea; jhbang@kigam.re.kr (J.-H.B.);

swlee21th@kigam.re.kr (S.-W.L.); jcw@kigam.re.kr (C.J.); psw1231@kigam.re.kr (S.P.); kssong@kigam.re.kr (K.S.); chohwanju@kigam.re.kr (W.J.J.)

* Correspondence: chae@kigam.re.kr; Tel.: +82-42-868-3659; Fax: +82-42-868-3421

Academic Editor: Vijay Kumar Thakur

Received: 5 September 2016; Accepted: 23 November 2016; Published: 25 November 2016

\begin{abstract}
Blast furnace slag (BFS) was selected as the source of $\mathrm{Ca}$ for $\mathrm{CO}_{2}$ mineralization purposes to store $\mathrm{CO}_{2}$ as $\mathrm{CaCO}_{3}$. BFS was dissolved using aqua regia (AR) for leaching metal ions for $\mathrm{CO}_{2}$ mineralization and rejecting metal ions that were not useful to obtain pure $\mathrm{CaCO}_{3}$ (as confirmed by XRD analysis). The AR concentration, as well as the weight of BFS in an AR solution, was varied. Increasing the AR concentration resulted in increased metal ion leaching efficiencies. An optimum concentration of $20 \%$ AR was required for completely leaching Ca and $\mathrm{Mg}$ for a chemical reaction with $\mathrm{CO}_{2}$ and for suppressing the leaching of impurities for the production of high-purity carbonate minerals. Increasing the liquid-to-solid ratio $(\mathrm{L} / \mathrm{S})$ resulted in the increased leaching of all metal ions. An optimum L/S of 0.3/0.03 (=10) was required for completely leaching alkaline-earth metal ions for $\mathrm{CO}_{2}$ mineralization and for retaining other metal ions in the filtered residue. Moreover, the filtrate obtained using 20\% AR and an L/S of 0.3/0.03 was utilized as Ca sources for forming carbonate minerals by $\mathrm{CO}_{2}$ mineralization, affording $\mathrm{CaCO}_{3}$. The results obtained herein demonstrated the feasibility of the use of $\mathrm{AR}$, as well as increasing $\mathrm{pH}$, for the storage of $\mathrm{CO}_{2}$ as high-purity $\mathrm{CaCO}_{3}$.
\end{abstract}

Keywords: blast furnace slag; $\mathrm{CO}_{2}$ mineralization; calcium leaching

\section{Introduction}

$\mathrm{CO}_{2}$ mineralization or carbonate mineralization is an alternative approach to store anthropogenic $\mathrm{CO}_{2}$, which can be transformed into carbonate minerals, such as calcium carbonate $\left(\mathrm{CaCO}_{3}\right)$ and magnesium carbonate $\left(\mathrm{MgCO}_{3}\right)$, via a chemical reaction with alkaline-earth metal ions; these metal ions can be obtained from natural minerals [1], industrial by-products, and wastes [2,3]. Mineralization can be broadly categorized into two methods: direct mineralization, in which $\mathrm{CO}_{2}$ directly reacts with sources of alkaline-earth metal ions, and indirect mineralization, in which $\mathrm{CO}_{2}$ indirectly reacts in an aqueous phase with the metal ions which are introduced by additional treatment before conducting the main reaction in situ $[1,4,5]$. Typically, for $\mathrm{CO}_{2}$ mineralization, the $\mathrm{pH}$ needs to be increased to greater than 10.3 for the ionization of $\mathrm{CO}_{2}$ to $\mathrm{CO}_{3}{ }^{2-}$ for facile combination with metal ions (in an aqueous phase) [6]. In addition, other procedures are employed for the ionization of alkaline-earth metal ions to facilitate combination with $\mathrm{CO}_{3}{ }^{2-}[3,7-11]$.

Alkaline-earth metal ions present in natural minerals are ionized at high temperature and pressure, as well as by reagents, such as acids and alkalis. Kleive and Thornhill [12] have pretreated a natural mineral such as olivine, which enhances its reactivity with $\mathrm{CO}_{2}$, followed by chemical treatment, and reported that the concentrations of leached $\mathrm{Mg}$ and Fe increase with increasing acid concentration. Huijgen et al. [13] have reported that wollastonite $\left(\mathrm{CaSiO}_{3}\right)$ can be used as a metal 
source for $\mathrm{CO}_{2}$ mineralization; wollastonite was powdered, added into an autoclave, and subjected to high temperature and high $\mathrm{CO}_{2}$ pressure for direct mineralization. As a result, nearly $40 \%$ of the $\mathrm{Ca}$ present in wollastonite is converted to $\mathrm{CaCO}_{3}$. Nduagu et al. [14] have used Finnish serpentinite to leach $\mathrm{Mg}$ ion by using $\left(\mathrm{NH}_{4}\right)_{2} \mathrm{SO}_{4}$ and formed $\mathrm{Mg}(\mathrm{OH})_{2}$ by using aqueous ammonia. As compared to the mother minerals, Finnish serpentinite, $\mathrm{Mg}(\mathrm{OH})_{2}$ is more reactive toward $\mathrm{CO}_{2}$. Based on the procedures for leaching $\mathrm{Mg}$ and forming $\mathrm{Mg}(\mathrm{OH})_{2}$, the authors [15] have also tested various $\mathrm{Mg}$ silicate rocks from Finland, Lithuania, Australia, and Norway. They found that the amount of metal ions leached from these rocks vary with mineral locations. $\mathrm{Mg}$ ion in the aqueous phase was also used as metal ion source for $\mathrm{CO}_{2}$ mineralization. A magnesium chloride $\left(\mathrm{MgCl}_{2} \cdot 6 \mathrm{H}_{2} \mathrm{O}\right)$ solution was prepared to synthesize nesquehonite $\left(\mathrm{MgCO}_{3} \cdot 3 \mathrm{H}_{2} \mathrm{O}\right)$ [16-19] and to study phase transitions from nesquehonite to dypingite $\left(\mathrm{Mg}_{5}\left(\mathrm{CO}_{3}\right)_{4}(\mathrm{OH})_{2} \cdot 5 \mathrm{H}_{2} \mathrm{O}\right)$ [20]. Hopkinson et al. have reported a more detailed study on the phase transitions for magnesium carbonates [21].

Eloneva et al. [22] have reported that blast furnace slag (BFS), the byproduct obtained from the steelmaking process, is useful for $\mathrm{CO}_{2}$ mineralization. First, BFS (50 g) was suspended in $1 \mathrm{~L} \mathrm{of} \mathrm{a} 20 \%$ acetic acid solution $(\sim \mathrm{pH} 4)$, and then the precipitate and silica gel were separated after the reaction. Acid was removed by heat treatment at $423-433 \mathrm{~K}$ for retaining alkali calcium acetate. The separated precipitate was suspended in deionized (DI) water with a $\mathrm{NaOH}$ solution (50 wt \%) for rendering conditions favorable for $\mathrm{CO}_{2}$ mineralization. Based on their study, Chiang et al. [23] have conducted two-step experiments for the selective leaching of Ca: First, $100 \mathrm{~g}$ of BFS was suspended in $731 \mathrm{~mL}$ of an acid solution at concentrations of 0.5-2 M. Second, the suspension was treated with $\mathrm{CO}_{2}$ after heating and stirring for $1 \mathrm{~h}$. Using a $2 \mathrm{M}$ acetic acid solution containing BFS, the leaching efficiencies of $\mathrm{Al}, \mathrm{Ca}, \mathrm{Mg}$, and Si were 38\%, 90\%, 100\%, and 7\%, respectively, after the second leaching. Ammonium chloride was also used as the leaching agent for Ca from basic oxygen steelmaking debris, secondary steelmaking slag, and hot metal desulfurization slag [24]. Hall et al. have added the abovementioned slags in a $2 \mathrm{M}$ ammonium chloride solution and utilized them for leaching Ca at a leaching time of $2 \mathrm{~h}$. The leaching efficiency of Ca ranges from $24 \%$ to $38 \%$ for a slag particle size of less than $150 \mu \mathrm{m}$. They also demonstrated the possibility of synthesizing zeolites from the leached residues. Eloneva et al. have investigated the use of various ammonia leaching agents, such as ammonium acetate $\left(\mathrm{CH}_{3} \mathrm{COONH}{ }_{4}\right)$, ammonium nitrate $\left(\mathrm{NH}_{4} \mathrm{NO}_{3}\right)$, and ammonium chloride $\left(\mathrm{NH}_{4} \mathrm{Cl}\right)$, for the leaching of $\mathrm{Ca}$ from $100 \mathrm{~g}$ of steel converter slag for precipitating high-purity $\mathrm{CaCO}_{3}$ [25]. Recently, Lee et al. have used several ammonium salts (e.g., $\mathrm{NH}_{4} \mathrm{NO}_{3}, \mathrm{NH}_{4} \mathrm{Cl}, \mathrm{CH}_{3} \mathrm{COONH}_{4}$, and $\left.\left(\mathrm{NH}_{4}\right)_{2} \mathrm{SO}_{4}\right)$ ) for leaching $\mathrm{Ca}$ from BFS at ambient temperature and pressure [26] and examined the leaching efficiency of Ca with respect to the types and concentration of solvents, temperature, reaction time, and solid-to-liquid ratio (S/L). With increasing solvent concentration, temperature, and reaction time, the Ca leaching efficiency increases to near $52 \mathrm{wt} \%$. Meanwhile, S/L does not proportionally increase the Ca leaching efficiency.

Several studies have primarily reported the use of strong or weak acids for leaching alkaline-earth metal ions [8,27-29] from various steelmaking slags. Acid solution strength exhibits both advantages and disadvantages for leaching. Typically, although a strong acid is efficient for leaching Ca, large amounts of other metal ions, such as Fe or Mn, present in slag can also be leached. Furthermore, the use of a strong acid requires a large amount of alkali to neutralize the reactant phases for rendering conditions favorable for $\mathrm{CO}_{2}$ mineralization. In contrast, although weak acids or even bases are not suitable for leaching $\mathrm{Ca}$, marginal amounts of alkali are required for rendering conditions favorable for $\mathrm{CO}_{2}$ mineralization. In this study, BFS and aqua regia (AR) were selected as the source of alkaline-earth metal ions and leaching agent, respectively, for $\mathrm{CO}_{2}$ mineralization. To the best of our knowledge, $\mathrm{AR}$ has not been used as a leaching agent in $\mathrm{CO}_{2}$ mineralization. As a type of strong acid, $\mathrm{AR}$ is known to exhibit a strong oxidizing ability toward various metal ions, such as $\mathrm{Ca}, \mathrm{Mg}$, and $\mathrm{Fe}$, and is non-corrosive to silica. Moreover, the effects of the variation of AR concentration and liquid-to-solid ratio (L/S; volume of AR solution/weight of slag) on the leaching efficiency of metal ions from BFS were investigated. In addition, experiments were conducted for the selective leaching of metal ions under the given leaching conditions. 


\section{Materials and Methods}

\subsection{Materials, Reagents, and Instrumentations}

BFS (SEM image in Figure 1, JEOL-7800F, Jeol, Tokyo, Japan) used herein was obtained from a steel making company in South Korea; slag was milled, and powders with a mesh size of below 200 were collected. As reported in previous studies utilizing BFS [2,30], crystal phases of BFS were not observed by XRD analysis (Analytical X-ray B.V.X'pert-MPD, Philips, EA Almelo, The Netherlands; scanning range of $3^{\circ}-70^{\circ}(2 \theta)(\mathrm{CuK} \alpha)$ using a step size of $0.02^{\circ}(2 \theta)$ at $\left.40 \mathrm{kV} / 40 \mathrm{~mA}\right)$. The concentrations of elements in oxide compounds were quantitatively measured by X-ray fluorescence (XRF; MXF-2400, Shimadzu, Kyoto, Japan, approximately $1 \mathrm{~g}$ of a sample was used to make a glass disc with $5.5 \mathrm{~g}$ of $\mathrm{Li}_{2} \mathrm{~B}_{4} \mathrm{O}_{7}$ as the flux) for the estimation of the leaching ratio ( $\mathrm{LCH}$. R) of metal ions from BFS by using AR.

AR was freshly prepared before each experiment, due to its rapid decomposition; for the preparation of $30,60,90,120$, and $150 \mathrm{~mL}$ of $\mathrm{AR}, \mathrm{AR}$ was prepared at volume ratio of 3:1 of hydrochloric acid $(\mathrm{HCl},>32 \%$, Fluka, St. Louis, $\mathrm{MO}, \mathrm{USA})$ :nitric acid $\left(\mathrm{HNO}_{3}, 60 \%-61 \%\right.$, Junsei, Tokyo, Japan). In addition, $2 \mathrm{~mL}$ of perchloric acid $\left(\mathrm{HClO}_{4}, 70 \%\right.$, Junsei) was added in $\mathrm{AR}$ because $\mathrm{HClO}_{4}$ is widely used for the oxidation of $\mathrm{Na}$ and $\mathrm{K}$ during wet chemical analysis. The actual molar ratio of $\mathrm{HCl}$ to $\mathrm{HNO}_{3}$ was 2.4:1. DI water (Milli-Q Gradient-A10, Millipore, Billerica, MA, USA) of 270, 240, 210, 180, and $150 \mathrm{~g}$ was added to AR, affording 10\%, 20\%, 30\%, 40\%, and 50\% AR solutions, respectively. The corresponding molar concentrations of the diluted AR solutions (300 $\mathrm{mL})$ were 1.12, $2.23,3.35,4.47$, and 5.59 M. The metal ion concentration was measured by inductively coupled plasma optical emission spectroscopy (ICP-OES, Optima 5300 DV, Perkin-Elmer, Waltham, MA, USA, relative standard deviation $<3 \%$ ).

\subsection{Leaching Procedures}

In the experiments, 20, 25, and $30 \mathrm{~g}$ BFS were used for comparing the effect of the variation of L/S on the leaching of metal ions. According to the experimental procedure shown in Figure 1, first, an aliquot of BFS was dispersed in a certain amount of DI water at $343 \mathrm{~K}$ by overhead stirring. Second, a specific concentration of freshly prepared AR was added to the suspension, and stirring was continued for the desired reaction time. Within several minutes, the color of this mixture changed from bright brown to yellow as the reaction proceeded, and the mixture appeared to be very sticky (this observation is hypothesized to correspond to gel formation). Gelation started within 10 min of the experiment, which was maintained until the reaction was stopped. Finally, at time intervals shown in Figure 1 during the experiment, approximately $10-15 \mathrm{~mL}$ of the gel was removed from the mixture and filtered using a $0.45 \mu \mathrm{m}$ membrane (mixed cellulose acetate membrane, Advantec, Tokyo, Japan). The metal ion concentration was quantified by ICP-OES. As a control experiment for comparing the effects of AR on the leaching of Si and metal ions from BFS, leaching was conducted using boiling DI water. For this purpose, $30 \mathrm{~g}$ of slag was dispersed in boiling DI water for $2 \mathrm{~h}$, followed by boiling and stirring. The concentrations of $\mathrm{Ca}, \mathrm{Mg}, \mathrm{Fe}, \mathrm{Mn}, \mathrm{Al}$, Ti, and $\mathrm{Si}$ as measured by ICP-OES were 56, 0.01, $0.01,0.01,2.2,0$, and $19 \mathrm{mg} / \mathrm{L}$, respectively, indicating that boiling water does not affect the leaching of metal ions (compared with the concentrations of the metal oxides present in raw BFS shown in Table 1).

All leaching procedures were completed within $2 \mathrm{~h}$. After the completion of experiments, the gelled slag-AR mixtures were separated using a glass microfiber filter (GF/C, Whatman, Brentford, UK) into an aqueous phase and a solid phase. Experiments for the comparison of L/S ratios were conducted using 20 and $25 \mathrm{~g}$ BFS per $20 \%$ of the AR solution by identical leaching procedures. After filtration, the solid phase was washed with DI water until the $\mathrm{pH}$ of the phase was approximately neutral, as tested by a $\mathrm{pH}$ paper. Finally, the solid phase was dried in an oven at $348 \mathrm{~K}$, which was further used for X-ray diffraction (XRD) analysis, as well as for specific surface area measurement by Brunauer, Emmett, and Teller (BET) analysis using six adsorption data points at $\mathrm{P} / \mathrm{P}_{0}=0.05,0.1,0.15,0.2,0.25$, 
and 0.3 (Quadrasorb-SI, Quantachrome, Boynton Beach, FL, USA, $\mathrm{N}_{2}$ adsorption, 1.5-2 g sample was used for each analysis).

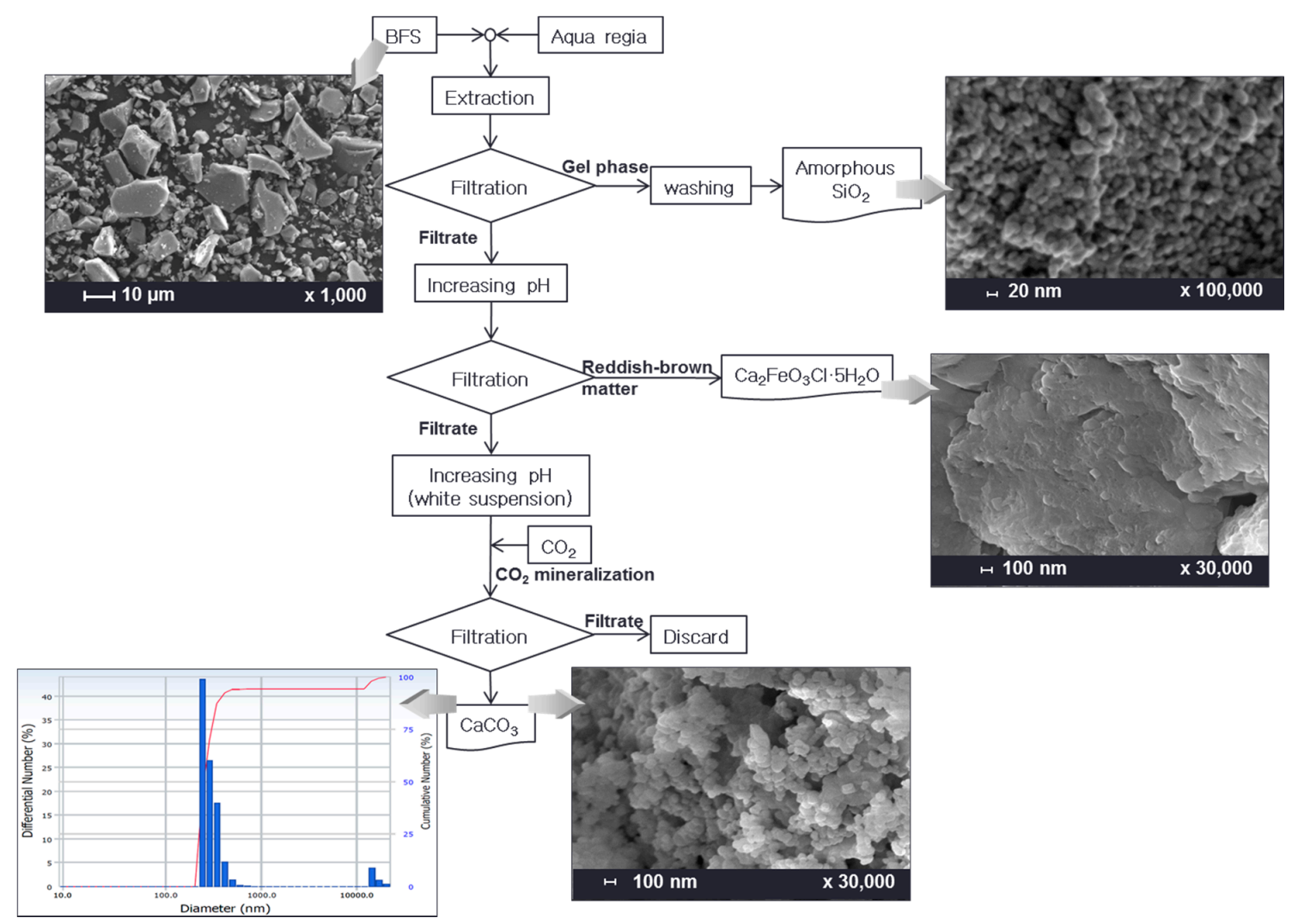

Figure 1. Experimental procedures and SEM images of BFS and precipitates.

A $5 \mathrm{M} \mathrm{NaOH}$ solution (Samchun Chemicals, Seoul, Korea) was added to the collected aqueous phase for increasing the $\mathrm{pH}$ up to 12 while continuously monitoring the $\mathrm{pH}$ of the filtrate using an Orion $\mathrm{pH}$ meter (3 Star Plus), followed by the bubbling of $\mathrm{CO}_{2}$ gas $(99.999 \%$, Gasco, Asan, Korea). The collected precipitates were identified by XRD. Figure 1 shows the experimental procedures. Particle size of $\mathrm{CaCO}_{3}$ was measured by dynamic light scattering (DLS, ELSZ-1000, Otsuka Electronics, Osaka, Japan). All averaged values and standard deviations were obtained from triplicate experiments.

\section{Results and Discussion}

It is imperative to know the chemical composition of BFS before conducting experiments for the comparison and estimation of the leaching efficiency (LCH. R) of metal ions from BFS under the given experimental conditions. Table 1 summarizes the results obtained from the quantitative measurement of $\mathrm{Si}$ and metal oxides present in BFS. The concentrations of the main components $\mathrm{CaO}$, $\mathrm{SiO}_{2}$, and $\mathrm{Al}_{2} \mathrm{O}_{3}$ were 44,35 , and $12 \mathrm{wt} \%$, respectively. On the other hand, the concentrations of other metal oxides, such as $\mathrm{FeO}, \mathrm{MgO}, \mathrm{TiO}$, and $\mathrm{MnO}$, were less than $10 \mathrm{wt} \%$. Table 2 summarizes the elemental concentrations of Si and metal ions $(\mathrm{mg} / \mathrm{kg})$, calculated using the values shown in Table 1 . These values were used as "reference values" for estimating the LCH. Rs of Si and other metal ions from the slag by AR treatment.

Table 1. Concentrations of metal oxides (wt \%) present in BFS by XRF analysis.

\begin{tabular}{cccccccccccc}
\hline Component & $\mathrm{SiO}_{2}$ & $\mathrm{Al}_{2} \mathrm{O}_{3}$ & $\mathrm{Fe}_{2} \mathrm{O}_{3}$ & $\mathrm{CaO}$ & $\mathbf{M g O}$ & $\mathrm{K}_{2} \mathrm{O}$ & $\mathrm{Na}_{2} \mathrm{O}$ & $\mathrm{TiO}_{2}$ & $\mathrm{MnO}$ & $\mathrm{P}_{2} \mathrm{O}_{5}$ & Loss on Ignition \\
\hline$\%$ & 35.24 & 12.33 & 2.01 & 43.63 & 4.13 & 0.18 & 0.33 & 0.44 & 0.23 & 0.01 & -1.14 \\
\hline
\end{tabular}


Alkaline-earth metal ions primarily react with carbonated $\mathrm{CO}_{2}$ during $\mathrm{CO}_{2}$ mineralization. In this study, Ca or Mg present in BFS was exploited; typically, pure Ca and Mg carbonates are white; however, marginal amounts of Fe can render them reddish-yellow. Even though Si and Al were present in BFS at a significantly high concentration, they do not form their respective carbonates via $\mathrm{CO}_{2}$ mineralization. Nevertheless, they can still be retained as impurities within $\mathrm{Ca}$ or $\mathrm{Mg}$ carbonates during the formation of carbonate minerals by $\mathrm{CO}_{2}$ mineralization. Consequently, it is valuable to separate Si from slag because high-purity Si can be used in industrial applications, such as in semiconductors or solar cells. Furthermore, a mixture of $\mathrm{Si}$ and $\mathrm{Al}$ can also be used for producing absorbents [23]. $\mathrm{Ca}$ and $\mathrm{Mg}$ carbonates with fewer impurities can result in increased market values of $\mathrm{CO}_{2}$ mineralization.

\subsection{Effect of the Variation of AR Solution Concentration and Leaching Time on Leaching Efficiency}

The AR-BFS mixture was stirred while simultaneously removing 10-15 mL aliquots of the mixture at a certain leaching interval, followed by filtration for measuring the concentrations of seven elements (Table 2) by ICP-OES. It is difficult to perform filtration, attributed to the silica-gel phase in the mixture [31]. The concentrations measured by ICP-OES (dimension: $\mathrm{mg} / \mathrm{L}$ ) were converted into the weight (dimension: $\mathrm{mg}$ ) of the elements in a mixture of the AR solution and BFS. It was crucial to convert dimension because the results in Table 2 could not be directly compared with those obtained by ICP-OES.

Table 2. Concentration of elements ( $\mathrm{mg} / \mathrm{kg}$ ) in BFS (calculated by XRF results from Table 1$)$.

\begin{tabular}{ccccccccccc}
\hline Element & Si & Al & Fe & Ca & Mg & K & Na & Ti & Mn & P \\
\hline $\mathrm{mg} / \mathrm{kg}$ & 164,758 & 65,273 & 14,061 & 311,876 & 24,913 & 1494 & 2449 & 2638 & 1782 & 44 \\
\hline
\end{tabular}

LCH. $\mathrm{R}$ is defined as follows [32]:

$$
\mathrm{LCH} . \mathrm{R}=\frac{\text { (concentration of each element measured by ICP }-\mathrm{OES}) \times(\text { volume of the mixture })}{(\text { concentration of each element measured by XRF }) \times(\text { weight of BFS })}
$$

Figure 2 shows the LCH. R of each element when the AR solution concentration was varied from $10 \%$ to $50 \%$, corresponding to $(\mathrm{A})-(\mathrm{E})$, respectively. As shown in Figure 2, a 10\% AR solution (A) leached $70 \%$ of $\mathrm{Ca}$ and $\mathrm{Mg}$ from the raw slag after a leaching time of $2 \mathrm{~h}, 60 \%$ of $\mathrm{Mn}$, and $20 \%$ of $\mathrm{Fe}$; however, $\mathrm{Al}$ and $\mathrm{Ti}$ were not leached. The Si concentration decreased from $7 \%$ to nearly $0 \%$ as leaching proceeded. As shown in Figure 2B, 20\% AR leached all Ca and Mg, as well as greater than 90\% of Mn. It also leached $80 \%$ and $40 \%$ of $\mathrm{Al}$ and Fe, respectively. Nevertheless, it was difficult to dissolve $\mathrm{Ti}$ in $20 \% \mathrm{AR}$. The concentration of $\mathrm{Si}$ in the filtered liquid phase decreased from $12 \%$ to nearly $0 \%$. Moreover, when 30\% AR was used (Figure 2C), a large standard deviation of the averaged value from triplicate experiments was observed for Fe and Ti. Even though leaching experiments were performed in triplicate, the reason for the peculiar decrease of the Ti concentration after 20 min was not known. The rate of change in the Si concentration was similar to that with the use of $10 \% \mathrm{AR}$. The concentration change of $\mathrm{Ca}, \mathrm{Mg}$, and $\mathrm{Mn}$ was similar to that with the use of $20 \% \mathrm{AR}$. In contrast, the dissolved concentrations of $\mathrm{Fe}, \mathrm{Al}$, and $\mathrm{Ti}$ increased to nearly $100 \%, 100 \%$, and 50\%, respectively. Increase in the AR concentration to $40 \%$ (Figure 2D) resulted in the increase of the dissolved concentrations of $\mathrm{Ca}, \mathrm{Mg}$, $\mathrm{Fe}, \mathrm{Mn}$, and $\mathrm{Al}$ from the early stage of leaching. Figure $2 \mathrm{E}$ shows the results obtained with the use of $50 \%$ AR. The leaching experiment had to be stopped in $30 \mathrm{~min}$ because the filtration of the mixture into liquid and solid phases was not possible by vacuum filtration. The $\mathrm{Ca}$ and $\mathrm{Al}$ concentrations reached $100 \%$ with the use of $40 \%$ AR. However, the dissolved $\mathrm{Mg}$, Fe, and $\mathrm{Mn}$ concentrations slightly decreased as compared with those obtained with the use of $40 \%$ AR. 

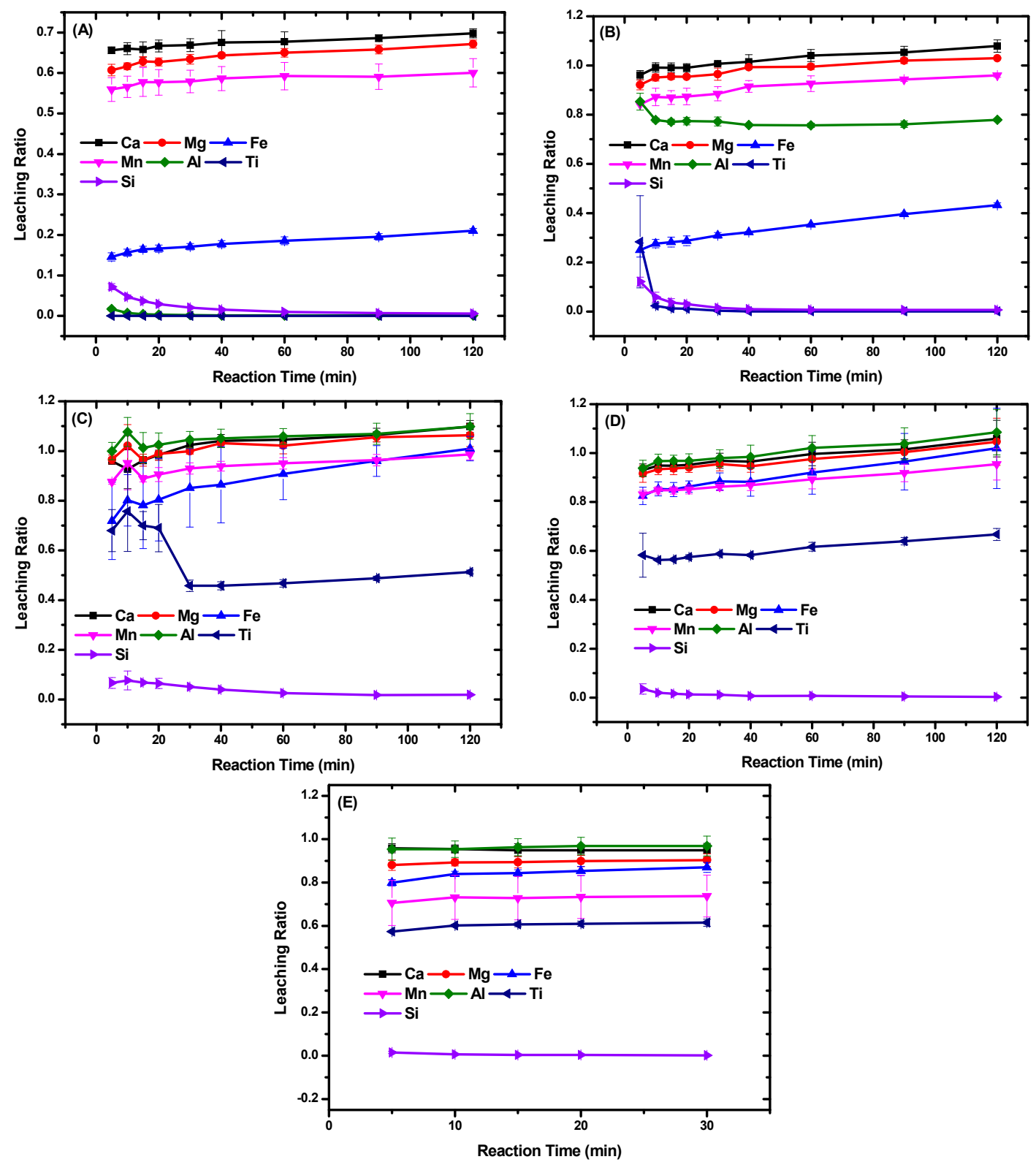

Figure 2. Effect of the variation in the AR concentrations of (A) $10 \%$; (B) $20 \%$; (C) $30 \%$; (D) $40 \%$; and (E) $50 \%$ with BFS suspended in DI water on the leaching ratio (LCH. R).

With increasing AR concentration, the leaching ratio of metal ions increased with time. However, the concentration of leached $\mathrm{Si}$ decreased or did not change with time. This observation is hypothesized to be due to the decomposition of the amorphous silica phase (actually BFS itself) when metal ions present in BFS are leached by contact with the AR solution; as a result, the amorphous silica phase is converted to hydrophilic silanol (Si-O-H) [33], which results in the loosening of the silica-gel-phase structure; this loosening of the structure results in the free movement of ions in the liquid phase.

In Figure 2, the five graphs indicate that the time required to attain a steady state of leaching efficiency (not relevant to the degree of leaching) decreases with increasing AR concentration. The maximum leaching efficiency was attained with a slag-50\% AR mixture. High AR concentrations are clearly advantageous for reaching a steady state of leaching time. However, the isolation of alkaline-earth metal ions for $\mathrm{CO}_{2}$ mineralization and exclusion of impurities, such as Fe- and Mn-coloring carbonate minerals, should be considered: this consideration may increase the feasibility of $\mathrm{CO}_{2}$ mineralization for producing relatively high-purity carbonate minerals. Leaching efficiencies 
were compared at a specific time (assuming the steady state in terms of Si concentration). The steady state for the LCH. R of Si was achieved in $20 \mathrm{~min}$ with the use of $10 \% \mathrm{AR}$. Above this concentration, no significant fluctuation in leaching efficiency was observed within $20 \mathrm{~min}$. Hence, the leaching efficiency of each element is compared at $20 \mathrm{~min}$, and Figure 3 shows the results obtained from comparison. The LCH. Rs of all elements were not affected by the AR concentration, except for those obtained using 10\% AR. In addition, the LCH. R of iron was low with the use of $20 \%$ AR, confirmed by the ICP-OES results. Table 3 shows the selectivity of each metal ion present in BFS by the equation below using the results from Figure 3.

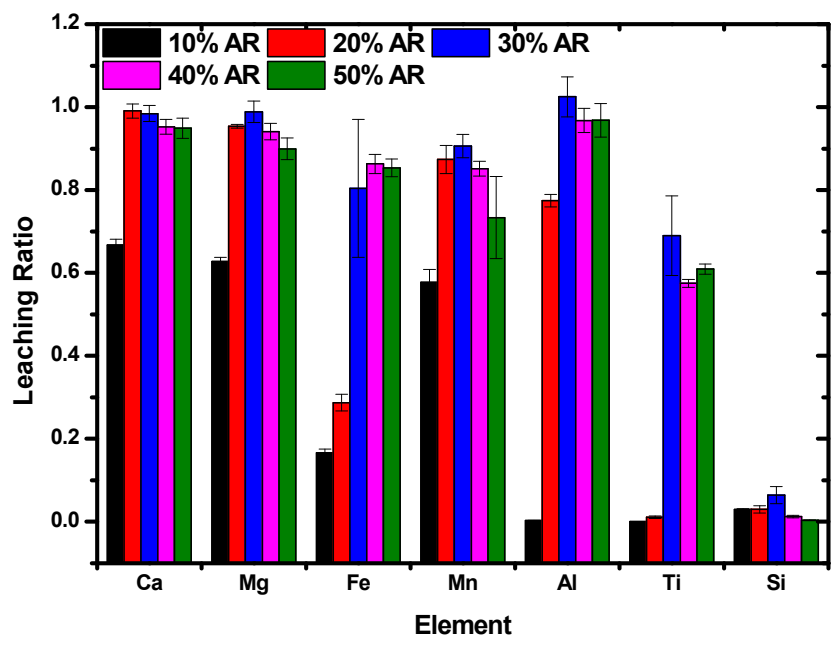

Figure 3. Comparison of the leaching ratio ( $\mathrm{LCH}$. R) of elements corresponding to the AR concentration at a leaching time of $20 \mathrm{~min}$.

Table 3. Selectivity of elements from leaching experiments.

\begin{tabular}{cccccccc}
\hline AR Concentrations (\%) & $\mathbf{C a}$ & $\mathbf{M g}$ & $\mathbf{F e}$ & $\mathbf{M n}$ & $\mathbf{A l}$ & $\mathbf{T i}$ & $\mathbf{S i}$ \\
\hline 10 & 32 & 30 & 8 & 28 & 0 & 0 & 1 \\
20 & 25 & 24 & 7 & 22 & 20 & 0 & 1 \\
30 & 18 & 18 & 15 & 17 & 19 & 13 & 1 \\
40 & 18 & 18 & 17 & 16 & 19 & 11 & 0 \\
50 & 19 & 18 & 17 & 15 & 19 & 12 & 0 \\
\hline
\end{tabular}

$$
\text { Elemental selectivity }(\%)=\frac{\text { concentration of each element }}{\Sigma(\text { concentration of seven elements })} \times 100
$$

The values obtained by the above equation were calculated from the results shown in Figure 3. For leaching a specific element, it is crucial to estimate the optimum AR concentration. Table 3 shows the results obtained. The selectivities of $\mathrm{Ca}$ and $\mathrm{Mg}$ increased with the use of $10 \% \mathrm{AR}$, as well as that of Mn. With the use of 20\% AR, the selectivities of Ca and Mg decreased; as compared with an AR concentration of greater than or equal to 30\%, 20\% AR was advantageous for deselecting Fe. The results from Table 3 and Figure 3 suggested that $20 \%$ AR is optimum for $\mathrm{CO}_{2}$ mineralization in terms of both LCH. R and selectivity. Increasing acid concentration clearly resulted in increased amounts of the leached metal elements. In $\mathrm{CO}_{2}$ mineralization, the amounts of leached $\mathrm{Ca}$ and $\mathrm{Mg}$ for the formation of carbonate minerals need to increase, while those of Fe- and Mn-coloring carbonate minerals and $\mathrm{Si}$ as impurities need to decrease. For $\mathrm{CO}_{2}$ mineralization, the filtrate obtained from acid by leaching is subjected to alkali agents (e.g., $\mathrm{NaOH}$ ) for increasing the reactivity of $\mathrm{CO}_{2}$ at high $\mathrm{pH}$ (i.e., pH swing) [8,27-29]. Hence, the acid concentration needs to be rationally chosen for $\mathrm{CO}_{2}$ mineralization. In our experiments, with respect to leaching $\mathrm{Ca}$ and un-leaching $\mathrm{Fe}, 20 \% \mathrm{AR}$ was appropriate to obtain white $\mathrm{CaCO}_{3}$ by $\mathrm{CO}_{2}$ mineralization. 


\subsection{Effects of the Liquid-to-Solid Ratio on Leaching Efficiency}

From the previous section, $20 \%$ of AR is confirmed to be optimum for leaching metal ions for $\mathrm{CO}_{2}$ mineralization with the use of $30 \mathrm{~g}$ slag and a $300 \mathrm{~mL}$ acid solution. This section deals with experiments involving the comparison of L/S. The AR concentration and AR solution volume were maintained constant; only, the weight of BFS suspended in the AR solution was changed: 20 and $25 \mathrm{~g}$. The use of slag with a weight greater than $30 \mathrm{~g}$ (i.e., $32 \mathrm{~g}$ ) was not appropriate because significantly harder and sticky gels led to the inefficient filtration of the filtrate from the gel. The variation of LCH. Rs was observed. Figure 4 shows the results obtained. The highest LCH. R was obtained with the use of $20 \mathrm{~g}$ slag (a similar result was obtained with the use of $40 \%$ AR with $30 \mathrm{~g}$ slag shown in Figure 4B). First, the observed $\mathrm{LCH}$. $\mathrm{R}$ of $\mathrm{Si}$, corresponding to an impurity for $\mathrm{CO}_{2}$ mineralization, was $66 \%$, which then decreased to $40 \%$ at the final stage with large deviation (Although we have conducted several additional experiments, the reason for this significant deviation is not clear at this time). With the decrease in the slag weight for leaching experiments, the amount of filter cake also significantly decreased (Figure 4D) because Si included in the slag was dissolved with the other six elements present in the AR solution; hence, silica gel is not formed, as observed in the panel of Figure 4D. The LCH. Rs of Fe, Al, and Ti were similar to that of Si, implying that these metals are caged in the silica gel. On the other hand, $\mathrm{Ca}, \mathrm{Mg}$, and $\mathrm{Mn}$ were released, irrespective of silica-gel formation. Bao et al. [32] have reported that by increasing L/S from 10 to 15, the leaching ratios of Ca and $\mathrm{Mg}$ increase to approximately $75 \%$ and $35 \%$, respectively. In contrast, the experiments conducted herein using AR did not show significant differences in the LCH. Rs of $\mathrm{Ca}, \mathrm{Mg}$, and Mn. However, the LCH. Rs of Fe, Al, Ti, and Si were affected by L/S (L/S: 0.3/0.02; 10, 0.3/0.025; 12, and 0.3/0.3; 15).
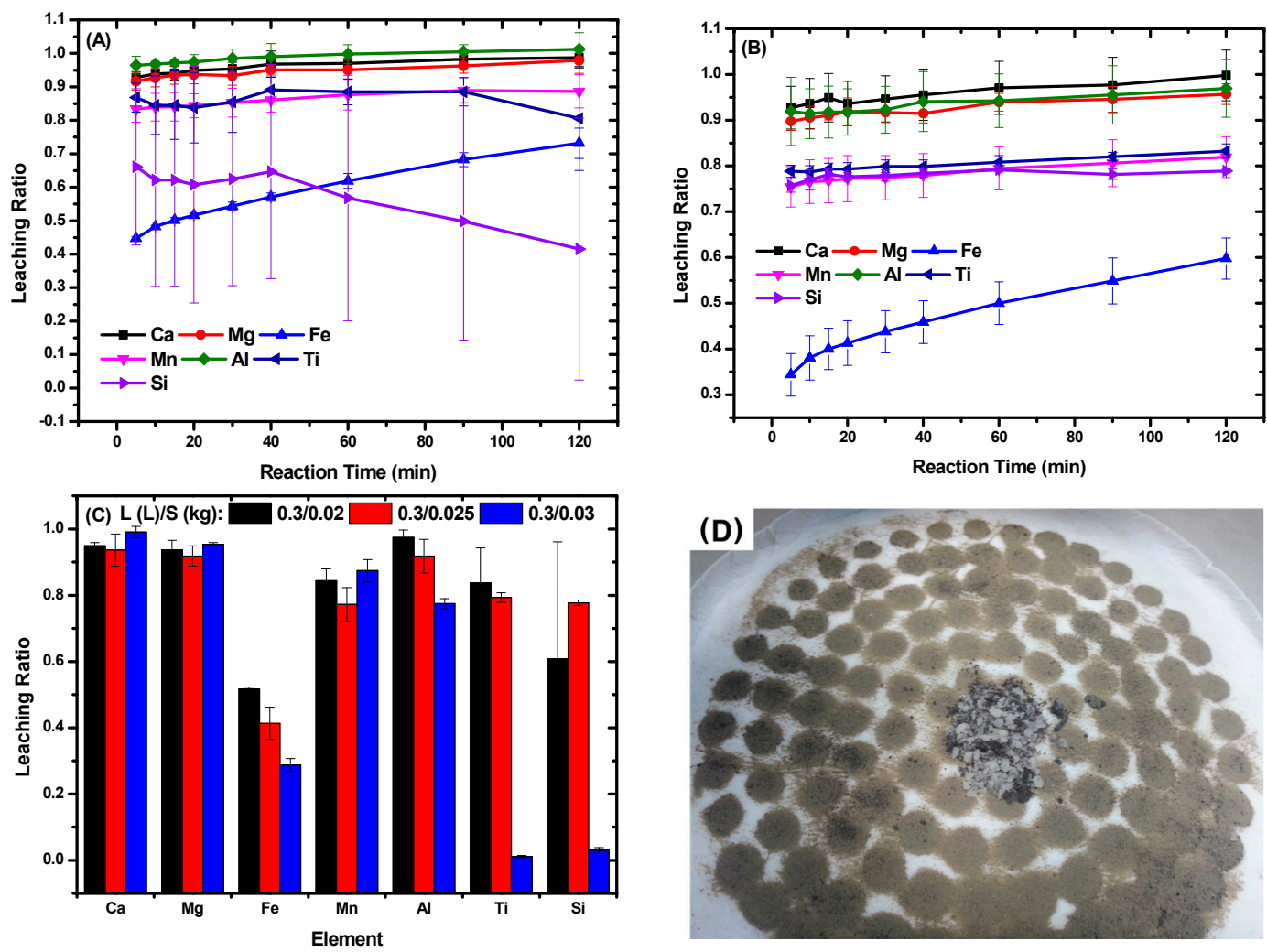

Figure 4. Effects of the variation in the weight of BFS of (A) 20 and (B) $25 \mathrm{~g}$ in a $20 \%$ AR solution $(300 \mathrm{~mL})$ on the leaching ratio (LCH. R) of elements. Graph $(\mathbf{C})$ denotes the comparison of the leached ratio of elements corresponding to the ratio of slag weight $(\mathrm{g})$ to $\mathrm{AR}(20 \%)$ liquid volume $(\mathrm{mL})$ of 20/300, 25/300, and 30/300 at a leaching time of $20 \mathrm{~min}$. Picture (D) represents the residue washed with DI water upon filtration after a leaching time of $120 \mathrm{~min}$ with $25 \mathrm{~g}$ slag/300 $\mathrm{mL}$ at $20 \% \mathrm{AR}$. 
It is hypothesized that the use of acetic acid for leaching metals from slag results in the formation of a silica gel harder than that obtained using AR even with similar L/S. At $120 \mathrm{~min}$, the concentrations of Fe in the filtrates were $686 \pm 42,701 \pm 53$, and $608 \pm 13 \mathrm{mg} / \mathrm{L}$ for 20, 25, and $30 \mathrm{~g}$ slag, respectively. The optimum L/S is possibly 0.3/0.03 (L/ kg), caused by the high $\mathrm{LCH}$. Rs of Ca and $\mathrm{Mg}$, as well as low $\mathrm{LCH}$. Rs of $\mathrm{Fe}, \mathrm{Ti}$, and $\mathrm{Si}$, despite the fact that filtration was slow, attributed to silica-gel formation. After filtration, the solid phase separated from the mixture of AR and BFS was collected. The solid phase was washed with DI water until the $\mathrm{pH}$ of the phase increased to approximately neutral $\mathrm{pH}$, as confirmed by a $\mathrm{pH}$ paper. This solid phase was dried in an oven at $348 \mathrm{~K}$ and then gently milled. In Section 3.1, we stated that the gelled-slag phase predominantly consisted of an amorphous hydrophilic silanol phase, which was not supposed to change after acid treatment and drying. Figure 5 shows the XRD patterns of the dried amorphous powder and raw BFS. Broad signals centered at around $23^{\circ}$ were observed, which was in agreement with data reported by Rohilla et al. [34]. In addition, XRF analysis was employed to quantify the oxide compounds of the treated powder and raw BFS. AR treatment possibly afforded highly pure amorphous silica powder (shown in the SEM image in Figure 1) with a large specific surface area, implying fine size. Table 4 briefly summarizes these results. After AR-DI water treatment, almost all metal ions included in raw BFS were removed, resulting in a high-purity amorphous silica phase. With increasing AR concentration, the purity of silica increased up to $90 \%$ [35]. Hence, the purity of the silica phase increases up to $99 \%$, caused by the loss on ignition primarily caused by adsorbed water. With increasing AR concentration, the measured specific surface area of the AR-DI water-treated powder also increased. The results obtained from measurements of XRF and specific surface area indicated that the AR-DI water treatment renders utility to BFS in terms of a high-purity material and an adsorbent. According to the experiments, the $\mathrm{L} / \mathrm{S}$ should be optimized to obtain silica powder from BFS besides $\mathrm{CO}_{2}$ mineralization.

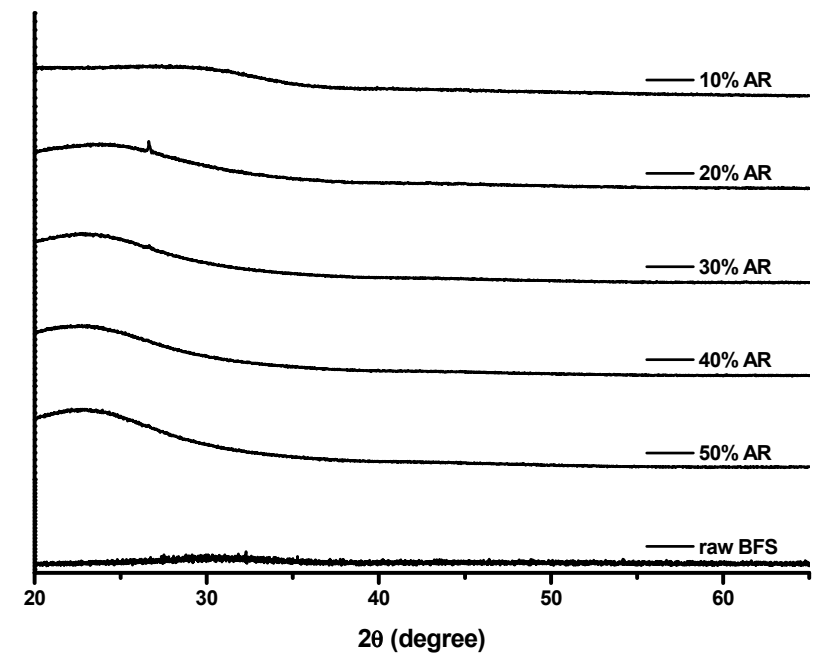

Figure 5. XRD patterns of the separated solid phase treated by AR-DI water and raw BFS.

Table 4. Oxide compounds found in BFS treated by AR-DI water as well as their specific surface areas.

\begin{tabular}{|c|c|c|c|c|c|c|c|c|c|c|c|c|}
\hline $\begin{array}{l}\text { AR } \\
\text { Conc. } \\
(\%)\end{array}$ & $\begin{array}{c}\mathrm{SiO}_{2} \\
(\%)\end{array}$ & $\begin{array}{c}\mathrm{Al}_{2} \mathrm{O}_{3} \\
(\%)\end{array}$ & $\begin{array}{c}\mathrm{Fe}_{2} \mathrm{O}_{3} \\
(\%)\end{array}$ & $\begin{array}{c}\mathrm{CaO} \\
(\%)\end{array}$ & $\begin{array}{c}\mathrm{MgO} \\
(\%)\end{array}$ & $\begin{array}{c}\mathrm{K}_{2} \mathrm{O} \\
(\%)\end{array}$ & $\begin{array}{c}\mathrm{Na}_{2} \mathrm{O} \\
(\%)\end{array}$ & $\begin{array}{c}\mathrm{TiO}_{2} \\
(\%)\end{array}$ & $\begin{array}{c}\mathrm{MnO} \\
(\%)\end{array}$ & $\begin{array}{c}\mathrm{P}_{2} \mathrm{O}_{5} \\
(\%)\end{array}$ & $\begin{array}{c}\text { Loss on } \\
\text { Ignition } \\
(\%)\end{array}$ & $\begin{array}{c}\text { Specific } \\
\text { Surfaces Area } \\
\left(\mathrm{m}^{2} / \mathrm{g}\right)\end{array}$ \\
\hline 10 & 46.30 & 16.60 & 1.89 & 23.78 & 2.00 & 0.21 & 0.12 & 0.51 & 0.13 & 0.02 & -8.92 & 24.9 \\
\hline 20 & 71.97 & 6.75 & 3.10 & 3.4 & 0.32 & 0.11 & 0.01 & 0.96 & 0.03 & 0.02 & -12.48 & 250.8 \\
\hline 30 & 89.15 & 0.12 & 0.18 & $<0.01$ & 0.04 & 0.01 & $<0.02$ & 0.59 & $<0.01$ & $<0.01$ & -9.59 & 692.6 \\
\hline 40 & 90.95 & 0.09 & 0.04 & 0.01 & 0.04 & 0.01 & $<0.02$ & 0.29 & $<0.01$ & $<0.01$ & -8.75 & 751.3 \\
\hline 50 & 90.49 & 0.15 & 0.07 & 0.15 & 0.05 & 0.01 & $<0.02$ & 0.32 & $<0.01$ & $<0.01$ & -8.83 & 696.5 \\
\hline
\end{tabular}




\section{3. $\mathrm{CO}_{2}$ Mineralization of $\mathrm{Ca}$ Leached from $\mathrm{BFS}$}

In previous sections, $20 \% \mathrm{AR}$ is confirmed to be the optimum concentration as it affords high leaching ratios of $\mathrm{Ca}$ and $\mathrm{Mg}$ and high rejection ratios of other elements. The carbonation of the filtrate obtained using $20 \%$ AR with $\mathrm{CO}_{2}$ was briefly conducted.

Before the addition of $\mathrm{NaOH}$, the $\mathrm{pH}$ of the filtrate was 3.15. First, $5 \mathrm{M} \mathrm{NaOH}$ was added into the filtrate for slowly increasing $\mathrm{pH}$. Next, when a $\mathrm{pH}$ of around 7.5 was attained, a reddish-brown cloudy substance was observed, which was filtered for XRD characterization; the precipitate was $\mathrm{Ca}_{2} \mathrm{FeO}_{3} \mathrm{Cl} \cdot 5 \mathrm{H}_{2} \mathrm{O}$ (JCPDS 00-044-0445, above pattern and photograph in Figure 6). Figure 1 also shows its SEM image. Additional $\mathrm{NaOH}$ was added into the filtered liquid for increasing $\mathrm{pH}$. At a $\mathrm{pH}$ of 10.5, a white precipitate was suspended in the liquid, which was used for reaction with $200 \mathrm{~mL} / \mathrm{min}$ of $\mathrm{CO}_{2}$ while monitoring $\mathrm{pH} . \mathrm{CO}_{2}$ was continuously bubbled using an air diffuser (circular, $3 \mathrm{~cm}$ in diameter) until the $\mathrm{pH}$ of the suspension was decreased to be constant at around 7.5. Then, the suspension was filtered, affording a white precipitate; the crystal phase of this precipitate by XRD was found to be $\mathrm{CaCO}_{3}$ (JCPDS 01-081-2027 (calcite), 00-041-1475 (aragonite), and 01-085-0849 (calcite); second pattern and photograph in Figure 6). Figure 1 also shows a magnified SEM image and particle size distribution (near $320 \mathrm{~nm}$ ) of $\mathrm{CaCO}_{3}$. ICP-OES analysis was performed for estimating the elemental concentration of $\mathrm{Ca}_{2} \mathrm{FeO}_{3} \mathrm{Cl} \cdot 5 \mathrm{H}_{2} \mathrm{O}$ and $\mathrm{CaCO}_{3}$ to corroborate the results obtained from XRD analysis. Table 5 shows the results. The $\mathrm{Si}$ concentrations of those two precipitates were below the detection limit, indicating that $\mathrm{Si}$ is already collected as an amorphous silica phase by leaching (Figure 1). Substantial amounts of $\mathrm{Mg}, \mathrm{Mn}$, and $\mathrm{Al}$ in $\mathrm{Ca}_{2} \mathrm{FeO}_{3} \mathrm{Cl} \cdot 5 \mathrm{H}_{2} \mathrm{O}$ were measured, but the elements did not form crystals. In addition, even though the $\mathrm{CaCO}_{3}$ precipitate consisted of a large amount of $\mathrm{Mn}$, Mn-doped crystals (e.g., $\left.\mathrm{Mn} \cdot \mathrm{Ca}\left(\mathrm{CO}_{3}\right)_{2}\right)$ or $\mathrm{MnCO}_{3}$ was not formed in the three $\mathrm{CaCO}_{3}$ crystal phases. The $\mathrm{CaCO}_{3}$ obtained herein can be utilized as an industrial material, e.g., as a paper-making filler, because the shape and size distribution of the obtained $\mathrm{CaCO}_{3}$ herein can enhance the smoothness of paper surfaces, as well as printing quality [36]. Other metal ions, such as $\mathrm{Mg}$, $\mathrm{Al}$, and $\mathrm{Ti}$ were not supposed to form crystalline minerals. Hence, with the stepwise increase in the $\mathrm{pH}$ of the filtrate, impurities were eliminated from the $\mathrm{CaCO}_{3}$ crystal lattice, affording white $\mathrm{CaCO}_{3}$.

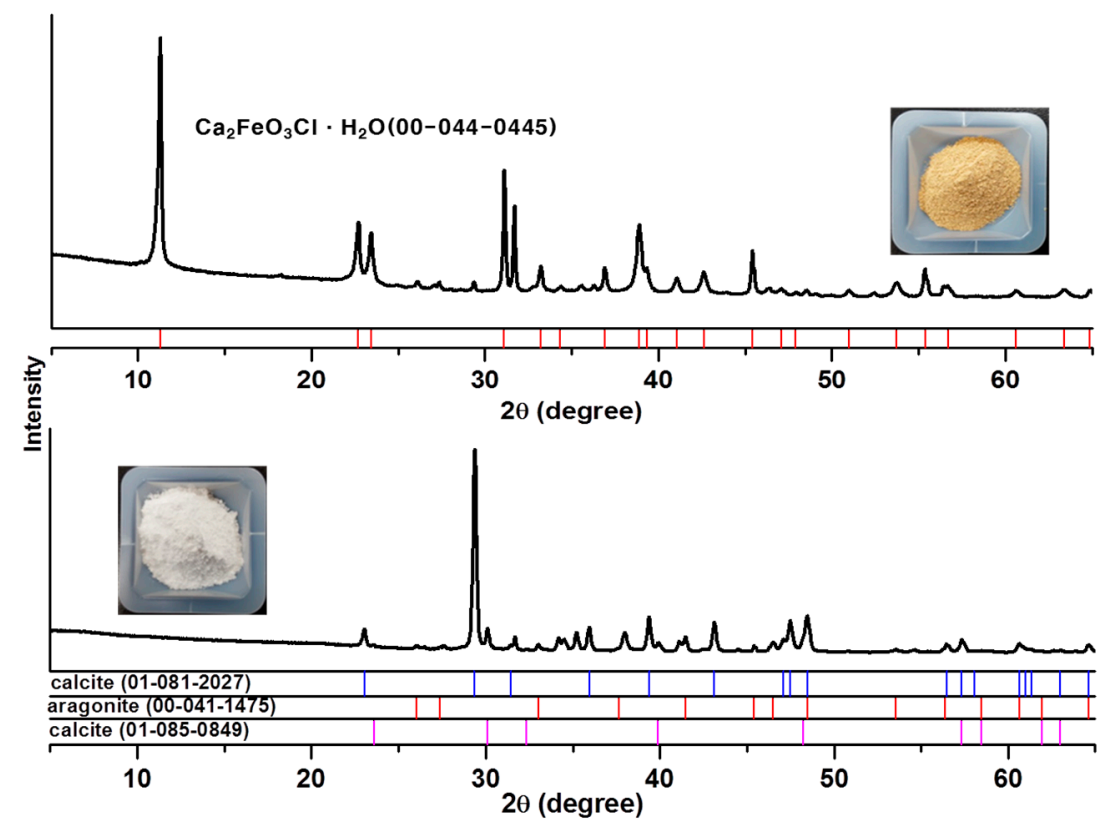

Figure 6. XRD patterns of reddish-brown and white precipitates with increasing $\mathrm{pH}$ of the filtrate obtained by the reaction of $20 \%$ AR. Magnified photographs of two powders from Figure 1 are also shown. 
Table 5. Analysis methods and elemental concentrations of the precipitates formed with increasing $\mathrm{pH}$ of the filtrate with $20 \%$ AR.

\begin{tabular}{ccccccccc}
\hline \multicolumn{1}{c}{ XRD } & \multicolumn{7}{c}{ ICP-OES (mg/kg) } \\
\hline Phase & JCPDS & Si & Fe & Mg & Mn & Al & Ti & Ca \\
\hline $\mathrm{Ca}_{2} \mathrm{FeO}_{3} \mathrm{Cl} \cdot 5 \mathrm{H}_{2} \mathrm{O}$ & $00-044-0445$ & $<0.28$ & - & 34,299 & 349,590 & 121,300 & $<0.05$ & 732,486 \\
\hline $\mathrm{CaCO}_{3}$ (calcite) & $01-081-2027$ & & & & & & & \\
$\mathrm{CaCO}_{3}$ (aragonite) & $00-041-1475$ & $<0.28$ & $<0.12$ & 1.1 & 143,636 & 205 & $<0.05$ & - \\
$\mathrm{CaCO}_{3}$ (calcite) & $01-085-0849$ & & & & & & & \\
\hline
\end{tabular}

\section{Conclusions}

In this study, alkaline-earth metal ions and other metal ions present in BFS were leached using $\mathrm{AR}$ for $\mathrm{CO}_{2}$ mineralization. The effects of the variation in the AR concentration and $\mathrm{L} / \mathrm{S}$ ratio on the leaching efficiencies of alkaline-earth metal ions, such as $\mathrm{Ca}$ and $\mathrm{Mg}$, were investigated for decreasing leaching ratios of other metal ions such as Fe. The AR concentration was varied from $10 \%$ to $50 \%$ for controlling the LCH. Rs of metal ions present in slag, which could increase the purity of carbonate minerals formed by $\mathrm{CO}_{2}$ mineralization. An optimum concentration of $20 \%$ AR was required for increasing the leaching of $\mathrm{Ca}$ and $\mathrm{Mg}$ while simultaneously decreasing the leaching of $\mathrm{Fe}, \mathrm{Al}$, and $\mathrm{Ti}$. An optimum L/S of $0.3 / 0.03(=10)$ at $20 \%$ AR was required for decreasing the leaching of $\mathrm{Fe}$, $\mathrm{Ti}$, and $\mathrm{Si}$; moreover, the leaching of $\mathrm{Ca}$ and $\mathrm{Mg}$ was not significantly different at other $\mathrm{L} / \mathrm{S}$ values. Si can retain metal ions, such as Fe, during its hydration (by forming silica gel), indicating that silica gel affects leaching selectivity. Preventing silica-gel formation by adjusting L/S adversely affects the purity of carbonate minerals, which is in agreement with the results reported by Crom et al. [30]. Impurities retained in the silica gel phase, such as $\mathrm{Fe}, \mathrm{Mn}$, and $\mathrm{Al}$, were removed by washing with deionized water, affording a high-purity $(\sim 99 \%)$ amorphous silica powder with a wide specific surface area (several hundred meter square per gram).

By this study, BFS treated by AR was confirmed to be useful for $\mathrm{CO}_{2}$ mineralization in terms of producing high-purity $\mathrm{CaCO}_{3}$ for industrially useful materials as fillers for paper making and for capturing $\mathrm{CO}_{2}$ materials via the Ca-looping cycle [37]. Amorphous silica powder can be used for preparing semiconductors, as well as an adsorbent for various potential applications [29], e.g., dehumidification and elimination of toxic matter. To increase the feasibility of the study conducted herein, economic evaluation in terms of carbonate mineralization [35] with $\mathrm{CaCO}_{3}$, amorphous silica, and reuse of AR will be conducted in a future study.

Acknowledgments: This study was supported by the Basic Research Project of the Korea Institute of Geoscience and Mineral Resources (KIGAM), funded by the Ministry of Science, Information and Communication Technologies ICT, and Future Planning.

Author Contributions: Jun-Hwan Bang and Soochun Chae conceived and designed the experiments; Jun-Hwan Bang and Seung-Woo Lee performed the experiments and analyzed the data; Chiwan Jeon, Kyungsun Song, Sangwon Park, Whan Joo Jo contributed reagents, materials, and analysis tools; and Jun-Hwan Bang wrote the paper.

Conflicts of Interest: The authors declare no conflict of interest.

\section{References}

1. Lackner, K.S.; Wendt, C.H.; Butt, D.P.; Joyce, E.L.; Sharp, D.H. Carbon dioxide disposal in carbonate minerals. Energy 1995, 20, 1153-1170. [CrossRef]

2. Teir, S.; Eloneva, S.; Fogelholm, C.J.; Zevenhoven, R. Dissolution of steelmaking slags in acetic acid for precipitated calcium carbonate production. Energy 2007, 32, 528-539. [CrossRef]

3. Bobicki, E.R.; Liu, Q.; Xu, Z.; Zeng, H. Carbon capture and storage using alkaline industrial wastes. Prog. Energy Combust. Sci. 2012, 38, 302-320. [CrossRef]

4. Lackner, K.S.; Butt, D.P.; Wendt, C.H. Progress on binding $\mathrm{CO}_{2}$ in mineral substrates. Energy Convers. Manag. 1997, 38, S259-S264. [CrossRef] 
5. Sanna, A.; Dri, M.; Hall, M.R.; Maroto-Valer, M. Waste materials for carbon capture and storage by mineralization (CCSM) - A UK perspective. Appl. Energy 2012, 99, 545-554. [CrossRef]

6. Bang, J.-H.; Jang, Y.N.; Kim, W.; Song, K.S.; Jeon, C.W. Precipitation of calcium carbonate by carbon dioxide microbubbles. Chem. Eng. J. 2011, 174, 413-420. [CrossRef]

7. Leung, D.; Caramanna, G.; Maroto-Valer, M. An overview of current status of carbon dioxide capture and storage technologies. Renew. Sust. Energy Rev. 2014, 39, 426-443. [CrossRef]

8. Azdarpour, A.; Asadullah, M.; Mohammadian, E.; Hamidi, H.; Junin, R.; Karaei, M.A. A review on carbon dioxide mineral carbonation through pH-swing process. Chem. Eng. J. 2015, 279, 615-630. [CrossRef]

9. Boot-Handford, M.E.; Abanades, J.C.; Anthony, E.J.; Blunt, M.J.; Brandani, S.; Dowell, N.M.; Fernández, J.R.; Ferrari, M.C.; Gross, R.; Hallett, J.P.; et al. Carbon capture and storage update. Energy Environ. Sci. 2014, 7, 130-189. [CrossRef]

10. Power, I.M.; Harrison, A.L.; Dipple, G.M.; Wilson, S.A.; Kelemen, P.B.; Hitch, M.; Southam, G. Carbon Mineralization: From natural analogues to engineered systems. Rev. Miner. Geochem. 2013, 77, 305-360. [CrossRef]

11. Eloneva, S.; Said, A.; Fogellholm, C.J.; Zevenhoven, R. Preliminary assessment of a method utilizing carbon dioxide and steelmaking slags to produce precipitated calcium carbonate. Appl. Energy 2012, 90, 329-334. [CrossRef]

12. Kleiv, R.A.; Thornhill, M. Mechanical activation of olivine. Miner. Eng. 2006, 19, 340-347. [CrossRef]

13. Huijgen, W.J.; Witkamp, G.J.; Comans, R.N. Mechanisms of aqueous wollastonite carbonation as a possible $\mathrm{CO}_{2}$ sequestration process. Chem. Eng. Sci. 2006, 61, 4242-4251. [CrossRef]

14. Nduagu, E.; Björklöf, T.; Fagerlund, J.; Wärnå, J.; Geerlings, H.; Zevenhoven, R. Production of magnesium hydroxide from magnesium silicate for the purpose of $\mathrm{CO}_{2}$ mineralisation-Part 1: Application to Finnish serpentinite. Miner. Eng. 2012, 30, 75-86. [CrossRef]

15. Nduagu, E.; Björklöf, T.; Fagerlund, J.; Mäkilä, E.; Salonen, J.; Geerlings, H.; Zevenhoven, R. Production of magnesium hydroxide from magnesium silicate for the purpose of $\mathrm{CO}_{2}$ mineralisation—Part 2: $\mathrm{Mg}$ extraction modeling and application to different $\mathrm{Mg}$ silicate rocks. Miner. Eng. 2012, 30, 87-94. [CrossRef]

16. Ferrini, V.; De Vito, C.; Mignardi, S. Synthesis of nesquehonite by reaction of gaseous $\mathrm{CO}_{2}$ with $\mathrm{Mg}$ chloride solution: Its potential role in the sequestration of carbon dioxide. J. Hazard. Mater. 2009, 168, 832-837. [CrossRef] [PubMed]

17. Ballirano, P.; De Vito, C.; Ferrini, V.; Mignardi, S. The thermal behaviour and structural stability of nesquehonite, $\mathrm{MgCO}_{3} \cdot 3 \mathrm{H}_{2} \mathrm{O}$, evaluated by in situ laboratory parallel-beam X-ray powder diffraction: New constraints on $\mathrm{CO}_{2}$ sequestration within minerals. J. Hazard. Mater. 2010, 178, 522-528. [CrossRef] [PubMed]

18. Glasser, F.P.; Jauffret, G.; Morrison, J.; Galvez-Martos, J.-L.; Patterson, N.; Imbabi, M.S.-E. Sequestering $\mathrm{CO}_{2}$ by mineralization into useful nesquehonite-based products. Front. Energy Res. 2016, 4, 1-7. [CrossRef]

19. Morrison, J.; Jauffret, G.; Galvez-Martos, J.L.; Glasser, F.P. Magnesium-based cements for $\mathrm{CO}_{2}$ capture and utilization. Cem. Concr. Res. 2016, 85, 183-191. [CrossRef]

20. Ballirano, P.; De Vito, C.; Mignardi, S.; Ferrini, V. Phase transitions in the $\mathrm{Mg}-\mathrm{CO}_{2}-\mathrm{H}_{2} \mathrm{O}$ system and thermal decomposition of dypingite, $\mathrm{Mg}_{5}\left(\mathrm{CO}_{3}\right)_{4}(\mathrm{OH})_{2} \cdot 5 \mathrm{H}_{2} \mathrm{O}$ : Implications for geosequestration of carbon dioxide. Chem. Geol. 2013, 340, 59-67. [CrossRef]

21. Hopkinson, L.; Kristova, P.; Rutt, K.; Cressey, G. Phase transitions in the system $\mathrm{MgO}-\mathrm{CO}_{2}-\mathrm{H}_{2} \mathrm{O}$ during $\mathrm{CO}_{2}$ degassing of Mg-bearing nsolutions. Geochim. Cosmochim. Acta 2012, 76, 1-13. [CrossRef]

22. Eloneva, S.; Teir, S.; Salminen, J.; Fogelholm, C.J. Fixation of $\mathrm{CO}_{2}$ by carbonating calcium derived from blast furnace slag. Energy 2008, 33, 1461-1467. [CrossRef]

23. Chiang, Y.W.; Santos, R.M.; Elsen, J.; Meesschaert, B.; Zevenhoven, R. Towards zero-waste mineral carbon sequestration via two-way valorization of ironmaking slag. Chem. Eng. J. 2004, 249, 260-269. [CrossRef]

24. Hall, C.; Large, D.J.; Adderley, B.; West, H.M. Calcium leaching from waste steelmaking slag: Significance of leachate chemistry and effects on slag grain mineralogy. Miner. Eng. 2014, 65, 156-162. [CrossRef]

25. Eloneva, S.; Puheloinen, E.M.; Kanerva, J.; Ekroos, A.; Zevenhoven, R.; Fogelholm, C.-J. Co-utilisation of $\mathrm{CO}_{2}$ and steelmaking slags for production of pure $\mathrm{CaCO}_{3}$-Legislative issues. J. Clean. Prod. 2010, 18, 1833-1839. [CrossRef]

26. Lee, S.; Kim, J.W.; Chae, S.; Bang, J.-H.; Lee, S.W. $\mathrm{CO}_{2}$ sequestration technology through mineral carbonation: An extraction and carbonation of blast slag. J. $\mathrm{CO}_{2}$ Util. 2016, 1, 336-345. [CrossRef] 
27. Kodama, S.; Nishimoto, T.; Yamamoto, N.; Yogo, K. Development of a new pH-swing $\mathrm{CO}_{2}$ mineralization process with a recyclable reaction solution. Energy 2008, 33, 776-784. [CrossRef]

28. Azdarpour, A.; Asadullah, M.; Mohammadian, E.; Junin, R.; Hamidi, H.; Manan, M.; Daud, A.R. Mineral carbonation of red gypsum via $\mathrm{pH}$-swing process: Effect of $\mathrm{CO}_{2}$ pressure on the efficiency and products characteristics. Chem. Eng. J. 2015, 264, 425-436. [CrossRef]

29. Sanna, A.; Dri, M.; Maroto-Valer, M. Carbon dioxide capture and storage by $\mathrm{pH}$ swing aqueous mineralisation using a mixture of ammonium salts and antigorite source. Fuel 2013, 114, 153-161. [CrossRef]

30. Crom, K.D.; Chiang, Y.W.; Gerven, T.V.; Santos, R.M. Purification of slag-derived leachate and selective carbonation for high-quality precipitated calcium carbonate synthesis. Chem. Eng. Res. Des. 2015, 104, 180-190. [CrossRef]

31. Qin, W.; Li, W.; Lan, Z.; Qiu, G. Simulated small-scale pilot plant heap leaching of low-grade oxide zinc ore with integrated selective leaching of zinc. Miner. Eng. 2007, 20, 694-700. [CrossRef]

32. Bao, W.; Li, H.; Zhang, Y. Selective leaching of steelmaking slag for indirect $\mathrm{CO}_{2}$ mineral sequestration. Indus. Eng. Chem. Res. 2010, 49, 2055-2063. [CrossRef]

33. Greenberg, S.A.; Jarnutowski, R.; Chang, T.N. The behavior of polysilicic acid. II. The rheology of silica suspensions. J. Colloid Sci. 1965, 20, 20-43. [CrossRef]

34. Rohilla, S.; Kumar, S.; Aghamkar, P.; Sunder, S.; Agarwal, A. Investigation on structural and magnetic properties of cobalt ferrite/silica nanocomposites prepared by the coprecipitation method. J. Magn. Magn. Mater. 2011, 32, 897-902. [CrossRef]

35. Sanna, A.; Hall, M.; Maroto-Valer, M. Post-processing pathways in carbon capture and storage by mineral carbonation (CCSM) towards the introduction of carbon neutral materials. Energy Environ. Sci. 2012, 5, 7781-7796. [CrossRef]

36. Bang, J.-H.; Song, K.; Park, S.; Jeon, C.W.; Lee, S.-W.; Kim, W. Effect of $\mathrm{CO}_{2}$ bubble size, $\mathrm{CO}_{2}$, flow rate and calcium source on the size and specific surface area of $\mathrm{CaCO}_{3}$ particles. Energies 2015, 8, 12304-12313. [CrossRef]

37. Miranda-Pizarro, J.; Perejón, A.; Valverde, J.M.; Sánchez-Jiménez, P.E.; Pérez-Maqueda, L.A. Use of steel slag for $\mathrm{CO}_{2}$ capture under realistic calcium-looping conditions. RSC Adv. 2016, 6, 37656-37663. [CrossRef]

(C) 2016 by the authors; licensee MDPI, Basel, Switzerland. This article is an open access article distributed under the terms and conditions of the Creative Commons Attribution (CC-BY) license (http://creativecommons.org/licenses/by/4.0/). 